\title{
Analysis of Combined Power and Refrigeration Generation Using the Carbon Dioxide Thermodynamic Cycle to Recover the Waste Heat of an Internal Combustion Engine
}

\author{
Shunsen Wang, Kunlun Bai, Yonghui Xie, Juan Di, and Shangfang Cheng \\ School of Energy and Power Engineering, Xian Jiaotong University, No. 28, Xianning West Road, Xi'an 710049, China \\ Correspondence should be addressed to Yonghui Xie; yhxie@mail.xjtu.edu.cn
}

Received 23 March 2014; Accepted 12 May 2014; Published 2 June 2014

Academic Editor: Zhijun Zhang

Copyright (c) 2014 Shunsen Wang et al. This is an open access article distributed under the Creative Commons Attribution License, which permits unrestricted use, distribution, and reproduction in any medium, provided the original work is properly cited.

\begin{abstract}
A novel thermodynamic system is proposed to recover the waste heat of an internal combustion engine (ICE) by integrating the transcritical carbon dioxide $\left(\mathrm{CO}_{2}\right)$ refrigeration cycle with the supercritical $\mathrm{CO}_{2}$ power cycle, and eight kinds of integration schemes are developed. The key parameters of the system are optimized through a genetic algorithm to achieve optimum matching with different variables and schemes, as well as the maximum net power output $\left(W_{\text {net }}\right)$. The results indicate that replacing a singleturbine scheme with a double-turbine scheme can significantly enhance the net power output $\left(W_{\text {net }}\right)$ and lower the inlet pressure of the power turbine $\left(P_{4}\right)$. With the same exhaust parameters of ICE, the maximum $W_{\text {net }}$ of the double-turbines scheme is $40 \%-$ $50 \%$ higher than that of the single-turbine scheme. Replacing a single-stage compression scheme with a double-stage compression scheme can also lower the value of $P_{4}$, while it could not always significantly enhance the value of $W_{\text {net }}$. Except for the power consumption of air conditioning, the net power output of this thermodynamic system can reach up to $13 \%-35 \%$ of the engine power when it is used to recover the exhaust heat of internal combustion engines.
\end{abstract}

\section{Introduction}

The internal combustion engine (ICE) has been a primary power source for automobiles, long-haul trucks, locomotives, and ships in the past few decades. Although a lot of advanced technologies have been developed to increase the thermal efficiency of the ICE, around $60 \%-75 \%$ of the fuel energy is still lost as waste heat through the exhaust and the coolant [1]. Despite the engine exhaust and the engine coolant having similar energy content, the higher temperature of the engine's exhaust gas makes it more thermodynamically attractive when viewed from the perspective of exergy. This results in a higher theoretical efficiency gain when coupled to a heat engine [1].

Recently, many efforts have been made to recover waste energy from the engine exhaust. Bianchi and De Pascale [2] evaluated three thermodynamic cycles, the organic Rankine cycle (ORC), Stirling, and the inverted Brayton, in order to recover low- and medium-grade waste heat. They determined that an ORC is the most attractive one of the three. Jansen et al. [1] developed a waste heat recovery system using the Brayton cycle, which consists of a heat exchanger to recover the exhaust heat, a turbocharger system to compress air and convert the heat energy into mechanical work, and an electric machine integrated into the turbocharger shaft to generate electric power. Results indicate that it can improve fuel efficiency by as much as $10 \%$. Song et al. [3] simplified the above system using the turbocharger compressor as the Brayton cycle compressor and the fuel economy of the diesel engine was improved only by $2.6 \%$ at high engine speed and $4.6 \%$ at low engine speed under engine full-load operating conditions. In 2005, Cummins Inc. proposed a scheme to recover the waste heat of a heavy-duty diesel engine through ORC. Then, AVL Inc. planned to develop a supercritical ORC to recover the waste heat of heavy-duty automotive diesel engine. Diego A. Arias from the University of Wisconsin proposed three different supercritical ORCs to recover different kinds of waste heat from a hybrid engine. BMW Inc. produced the "Turbo Steamer" system with a high temperature cycle and a low temperature cycle. The 
high temperature cycle recovers the waste heat of the engine exhaust, and the low temperature cycle mainly recovers the waste heat of the engine cooling system. Although research regarding the use of ORC to recover the waste heat of ICE has made some progress, the large size of the package unit and the leakage of organic fluids restrict its engineering application [4].

For the past few years, the transcritical/supercritical $\mathrm{CO}_{2}$ power cycle has attracted more and more attention. Persichilli et al. [5, 6] compared the cycle efficiency, equipment cost, and environmental performance of the transcritical $\mathrm{CO}_{2}$ cycle, the ORC, and the steam Rankine cycle. Results show that the $\mathrm{CO}_{2}$ transcritical power cycle can achieve a high efficiency over a wide range of heat source temperatures (from $204^{\circ} \mathrm{C}$ to $650^{\circ} \mathrm{C}$ ) with lower cost. They also did preliminary tests of a $250 \mathrm{~kW}$ waste heat recovery system using $\mathrm{CO}_{2}$ as the working fluid, which proved that the system performed as expected. Chen et al. [7] also compared the $\mathrm{CO}_{2}$ transcritical power cycle and the ORC with R123 as a working fluid. They found that when utilizing the lowgrade heat source with equal mean thermodynamic heat rejection temperature, the $\mathrm{CO}_{2}$ transcritical power cycle has a slightly higher power output than the ORC. Besides, other studies [8-11] on the $\mathrm{CO}_{2}$ power cycle for waste heat recovery have been reported, which confirmed its feasibility. $\mathrm{CO}_{2}$ is superior to other working fluids because of its lower critical temperature $\left(31.18^{\circ} \mathrm{C}\right.$, close to ambient temperature), smaller latent heat of vaporization in the transcritical power cycle, and no pinching point problem during the supercritical heat transmission [12-14]. In addition, $\mathrm{CO}_{2}$ is natural, cheap, and environmentally friendly. It does not decompose or explode within the temperature range of the ICE exhaust gas [15-19]. Furthermore, $\mathrm{CO}_{2}$ is suitable for the compact microchannel heat exchanger because of its excellent flow and heat-transfer properties. Under the conventional working parameters, the density of $\mathrm{CO}_{2}$ is 5 to 20 times the density of organic fluids, which makes the compressor, turbine, and piping system of the $\mathrm{CO}_{2}$ cycle much smaller than that of the ORC. So the $\mathrm{CO}_{2}$ cycle is highly suitable for recovering the waste heat from the ICE exhaust [5].

As is well known, most of the existing automobile air conditioning systems use HFC-R134a as a refrigerant. Because of the vibration and the frequent overhaul of the unit, the leakage of refrigerant is much greater than in household air conditioning, which is one of the main sources of greenhouse gas. Recently, BMW, Volkswagen, and some other major automobile manufacturers have planned to use $\mathrm{CO}_{2}$ as the refrigerant for automobile air conditioning in order to reduce the emission of greenhouse gas [20-24]. Several new and innovative designs for heat exchangers, compressors, and valves have emerged from studies in this area. This application has recently received increased attention based on the European Parliament's July 2006 vote to phase out the refrigerant HFC-134a.

Hence, a system of combined power and refrigeration generation using the $\mathrm{CO}_{2}$ thermodynamic cycle to recover the waste heat of an internal combustion engine is interesting. This system can not only take full advantage of the superiority of $\mathrm{CO}_{2}$ power cycles in high efficiency and small size, but also can be further made simple and compact because the working fluid and some equipment are shared by the refrigeration cycle and the power cycle, which can be the most feasible way for the waste heat recovery of ICE. In 2005, Chen et al. [25] proposed a thermodynamic cycle system with $\mathrm{CO}_{2}$ as a working fluid to recover the waste heat of the ICE. The system works separately or works in combination with the already exiting $\mathrm{CO}_{2} \mathrm{~A} / \mathrm{C}$ unit to produce power for the A/C system's compressor or even add further power to the propulsion system. In this paper, some new integration schemes of combined power and refrigeration generation with the $\mathrm{CO}_{2}$ thermodynamic cycle are proposed, and the key parameters of the system are optimized using a genetic algorithm to get optimum matching with different variables and schemes, as well as the maximum net power output. This research is very significant for promoting the development of ICE waste heat recovery.

\section{System Description and Modeling}

2.1. Thermodynamic Cycles. In most cases, a large terminal temperature difference is selected to reduce the size of the automotive heat exchanger, so that the typical values of the condensing temperature are usually higher than the critical temperature of carbon dioxide. Therefore, the waste heat recovery of an automotive internal combustion engine has to use the supercritical power cycle.

Figure 1(a) shows a typical single turbine supercritical $\mathrm{CO}_{2}$ power cycle system, referred to as STC. In this cycle, first the $\mathrm{CO}_{2}$ is compressed by a high-pressure compressor (HPC) from state 2 to state 3 . Then, it is heated to state 4 by the exhaust gas of the ICE in the gas heater. Next, the $\mathrm{CO}_{2}$ expands in a high-temperature turbine (HT), which can drive the vehicle directly or generate electricity $(\mathrm{G})$. Lastly, the $\mathrm{CO}_{2}$ exhaust of the HT is cooled from state 5 to state 2 in a gas cooler, thus completing a power cycle.

In order to improve the efficiency of waste heat recovery and lower the exhaust temperature of HT, a double-turbine supercritical $\mathrm{CO}_{2}$ power cycle system as shown in Figure 1(b) is proposed, which is referred to as DTC. In this cycle, first the $\mathrm{CO}_{2}$ is compressed by a high-pressure compressor (HPC) from state 2 to state 3 . Next, it is divided into two parts; one part is heated to state 4 by the exhaust gas of the ICE in the gas heater and then expands in a high-temperature turbine (HT). The other part is heated to state 4 by the $\mathrm{CO}_{2}$ exhaust of the $\mathrm{HT}$ in the regenerator and then expands in a low-temperature turbine (LT). Lastly, the two parts of the $\mathrm{CO}_{2}$ meet in a gas cooler and release the residual heat to the ambient air, during which the parameters of $\mathrm{CO}_{2}$ vary from state 1 to state 2 , completing a power cycle. Here, the HT and the LT have the same expansion ratio and inlet pressure but different inlet temperatures, which can significantly improve the efficiency of waste heat recovery and thermal power conversion. In addition, compared to the STC system, it is a very compact system, with the addition of a low-temperature turbine (LT) and a regenerator in the basic of STC system.

According to literature [20], a transcritical $\mathrm{CO}_{2}$ refrigeration cycle system as shown in Figure 2(a) can be used as the 


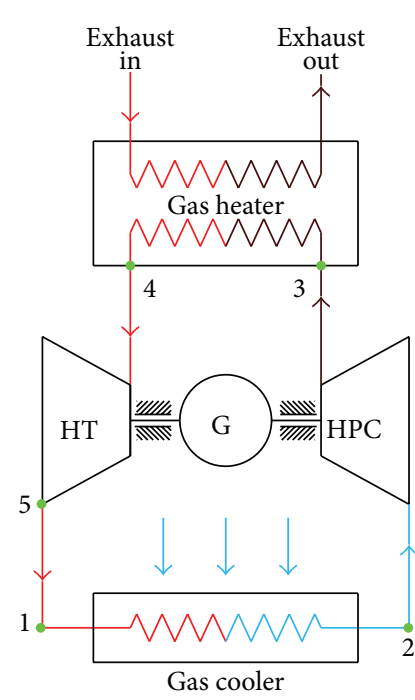

(a) System layout of STC

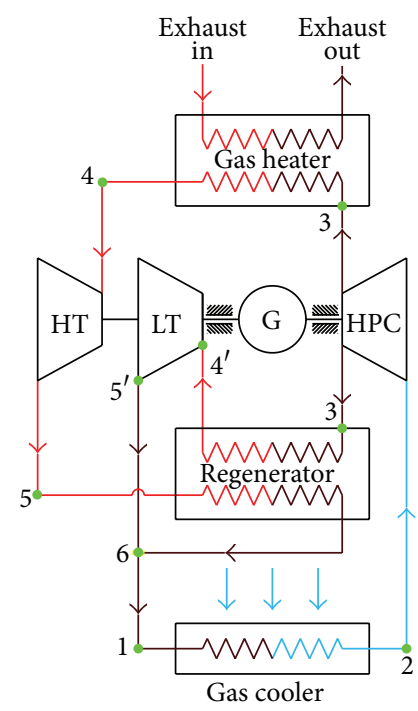

(b) System layout of DTC

FIGURE 1: Typical system layout of the supercritical $\mathrm{CO}_{2}$ power cycle.

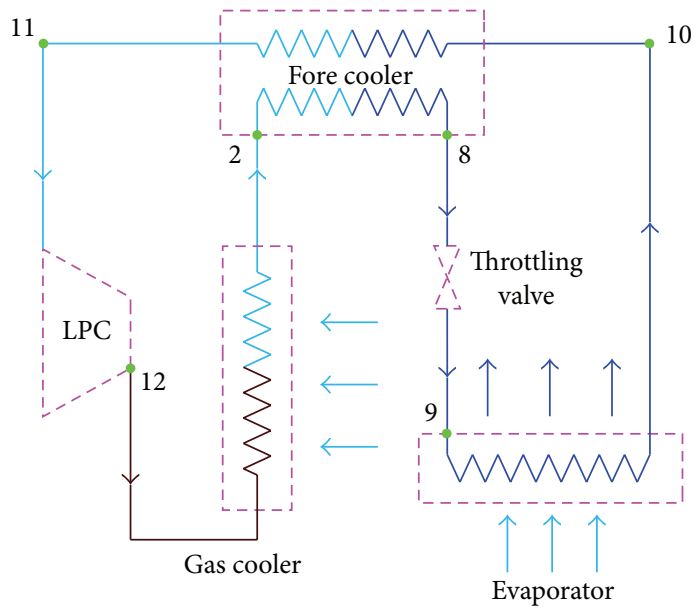

(a) With fore cooler

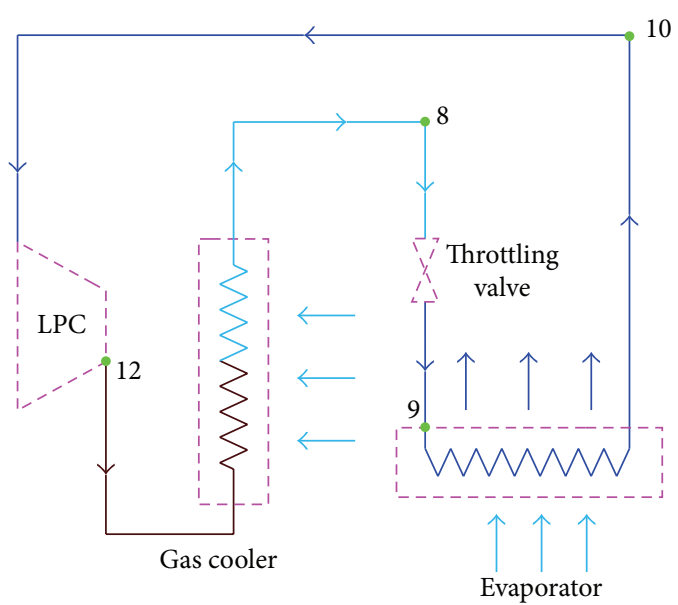

(b) Without fore-cooler

FIGURE 2: Typical system layout of the transcritical $\mathrm{CO}_{2}$ refrigeration cycle.

air conditioning in an automobile. In this cycle, supercritical $\mathrm{CO}_{2}$ (state 12) is compressed by a low-pressure compressor (LPC) from state 11 to state 12 . Then, it is cooled down to state 2 and state 8 in the gas cooler and fore cooler, successively. Next, the $\mathrm{CO}_{2}$ with low temperature and high pressure condenses to state 9 through a throttling valve. Further, the $\mathrm{CO}_{2}$ liquid evaporates by absorbing the heat of the automobile compartment in the evaporator and the automobile compartment is cooled. Finally, the $\mathrm{CO}_{2}$ after evaporation (state 10) is heated up to state 11 in a fore cooler before entering LPC, completing a refrigeration cycle. Considering the limits of vehicle space, removal of the fore cooler is an alternative, as shown in Figure 2(b). However, the effect of the fore cooler on the whole performance cycle requires further analysis.
Based on the operating principle of thermodynamic cycles and the basic idea of combined power and refrigeration generation, two patterns are proposed to integrate the waste heat recovery supercritical $\mathrm{CO}_{2}$ power cycle and thetranscritical $\mathrm{CO}_{2}$ refrigeration cycle to simplify and make the system compact, as shown in Figures 3 and 4. For the integration pattern in Figure 3, the exhaust $\mathrm{CO}_{2}$ pressure of $\mathrm{HT}$ is equal to the discharge pressure of LPC. HPC can only be used by the power circuit and LPC can only be used by the refrigeration circuit. However, the two circuits share a gas cooler, a working fluid tank, and other auxiliary equipment. For the integration pattern in Figure 4, the exhaust $\mathrm{CO}_{2}$ pressure of $\mathrm{HT}$ is equal to the intake pressure of LPC, and two circuits share the LPC as well as the gas cooler, the working fluid tank, and other auxiliary equipment. In this system, the power cycle includes 


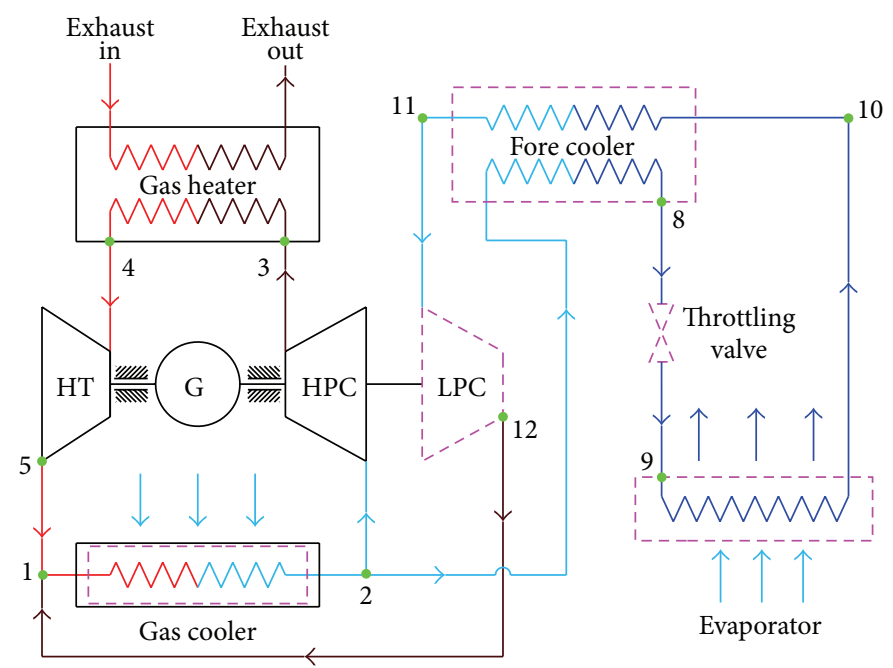

(a) System layout of SSF cycle

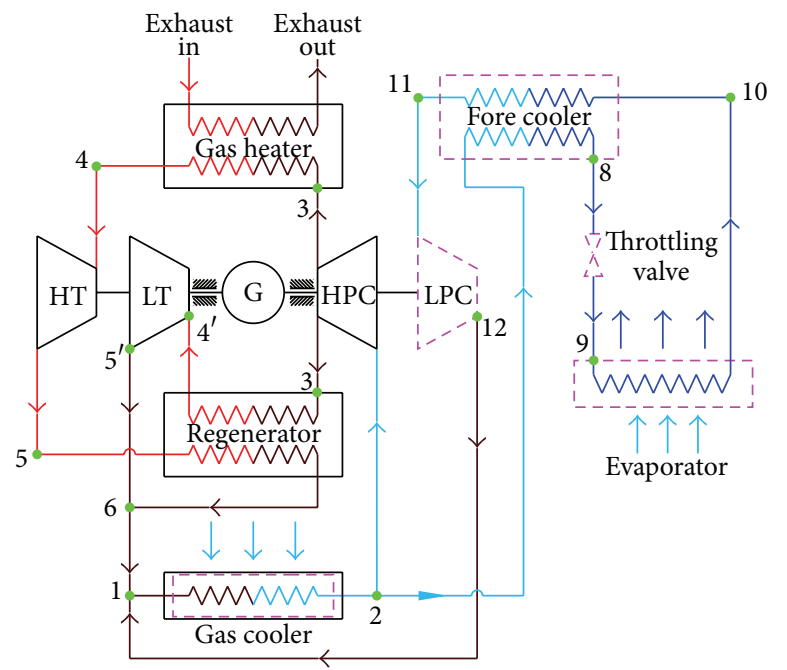

(c) System layout of DSF cycle

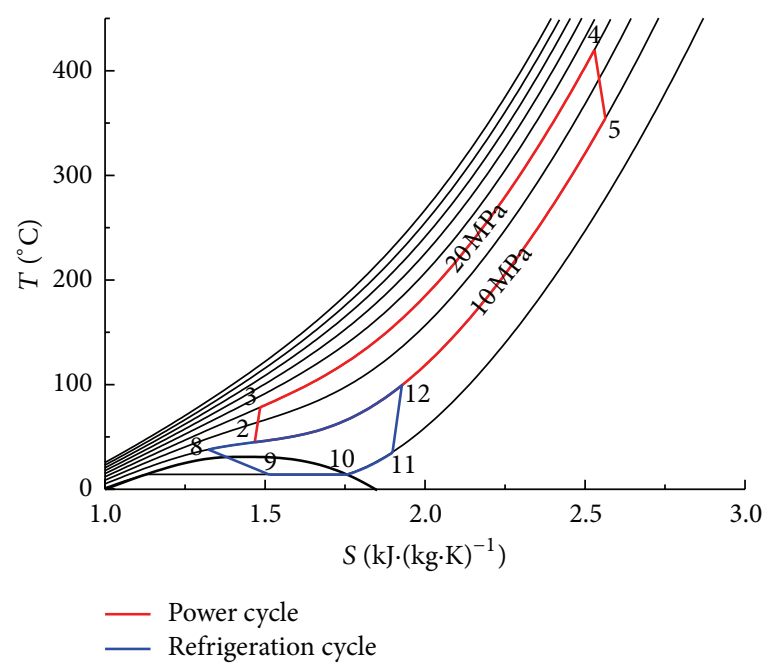

(b) T-S diagram of SSF cycle

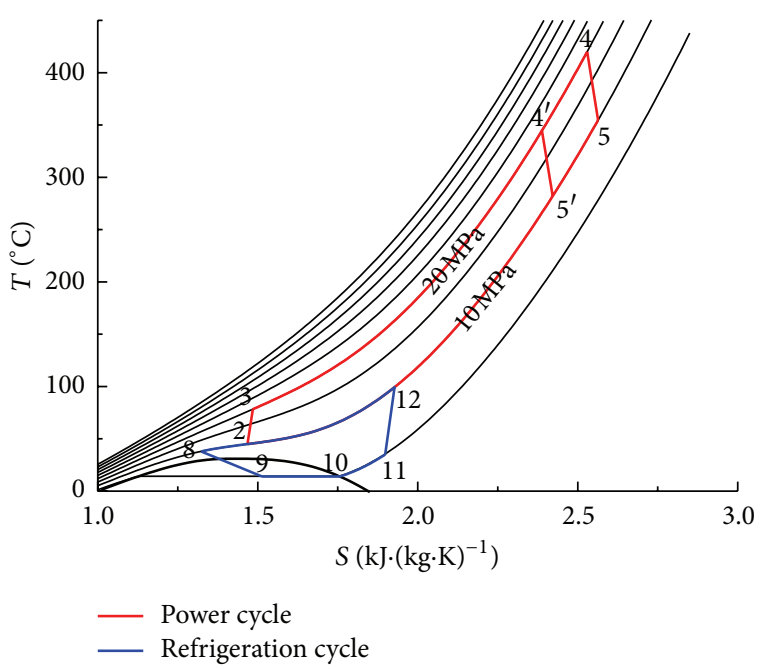

(d) T-S diagram of DSF cycle

FIGURE 3: System layout and T-S chart of SSF and DSF cycles.

a double-stage compression with intercooling. According to the characteristics of the integrated pattern, the systems shown in Figures 3(a) and 3(c) are referred to as the SSF scheme and the DSF scheme, respectively, while the systems shown in Figures 4(a) and 4(c) are referred to as the SDF scheme and the DDF scheme, respectively. The first letter "S" or " $D$ " represents single turbine or double turbines. The second letter "S" or "D" represents single-stage compression or double-stage compression of the power cycle. The third letter " $\mathrm{F}$ " denotes the refrigeration cycle with fore cooler. The absence of the third letter means the absence of the fore cooler. Thus, there are totally eight kinds of integration schemes: SSF, DSF, SDF, DDF, SS, DS, SD, and DD, based on the STC and DTC systems and the refrigeration system shown in Figure 2. No matter what kind of scheme, the HPC and LPC are driven by the coaxial turbine, and the system net power output is used to drive the vehicle directly or generate electricity.
Figures 3(b), 3(d), 4(b), and 4(d) show the $T$-S diagram of the SSF, DSF, SDF, and DDF schemes, respectively. In these diagrams, the inlet pressure of the turbine was chosen to be $20 \mathrm{MPa}$ and the discharge pressure of the LPC and the evaporator pressure are set at $10 \mathrm{MPa}$ and $5 \mathrm{MPa}$, respectively. It can be seen from these diagrams that the turbine exhaust $\mathrm{CO}_{2}$ temperature of the double-turbine scheme is significantly lower than that of the single turbine scheme. In addition, the turbine exhaust $\mathrm{CO}_{2}$ temperature of the double-stage compression scheme of the power cycle is also significantly lower than that of the single-stage compression scheme. However, further thermodynamic analysis and parameter optimization are necessary for improving the waste heat recovery of the ICE.

2.2. Energy Analysis of Thermodynamics Models. For the simulation of cycle performance, the following assumptions are made. 


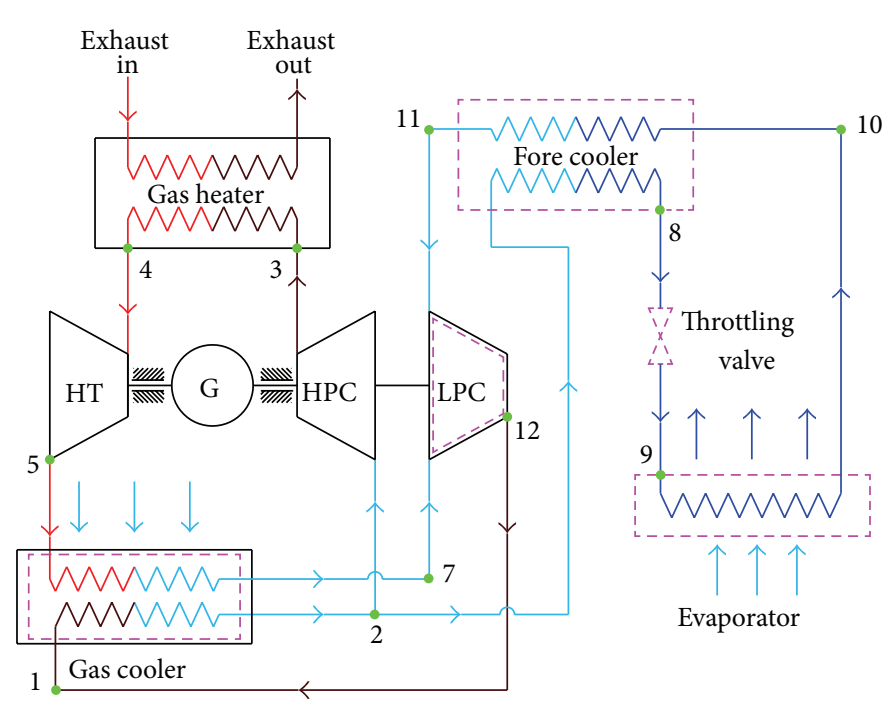

(a) System layout of SDF cycle

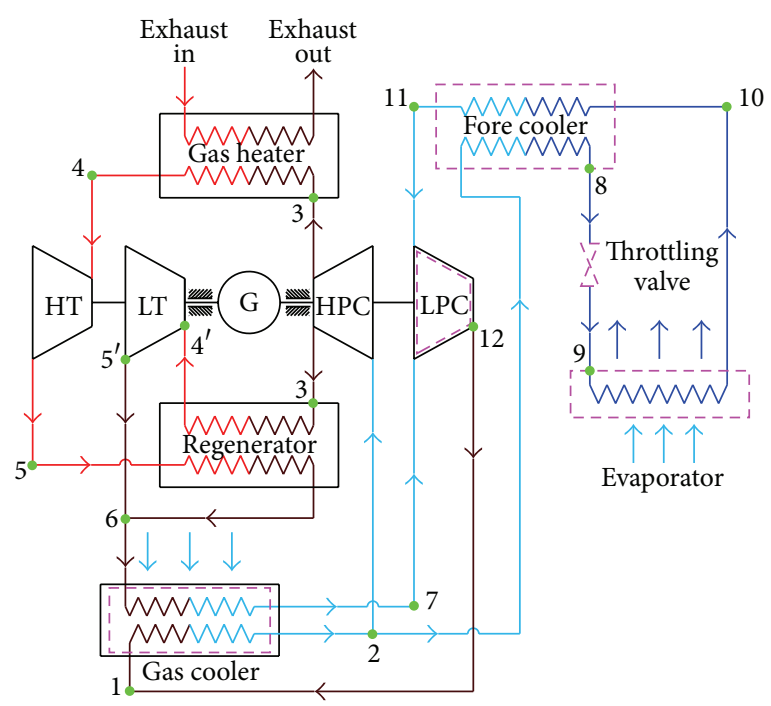

(c) System layout of DDF cycle

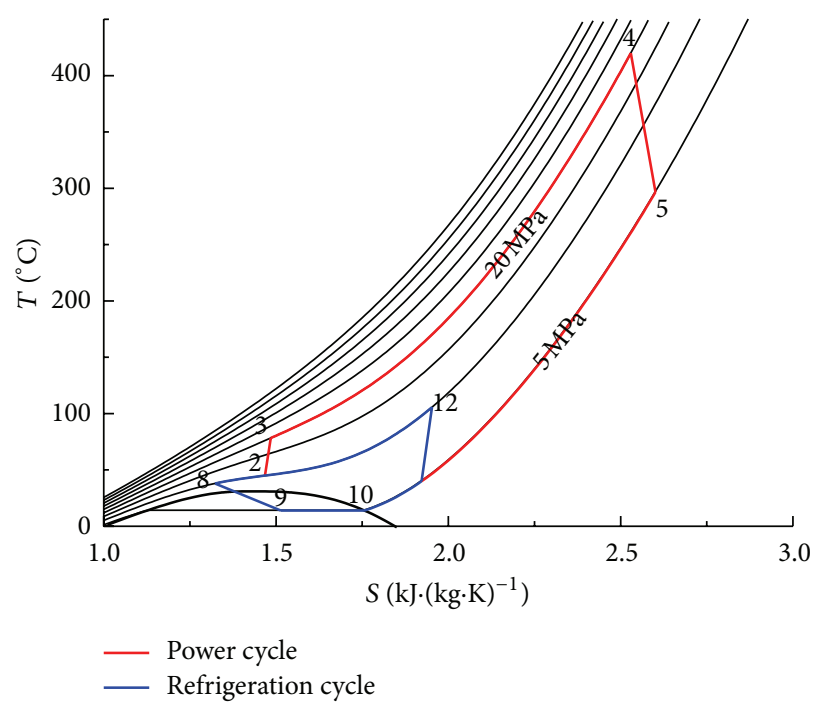

(b) $T$-S diagram of SDF cycle

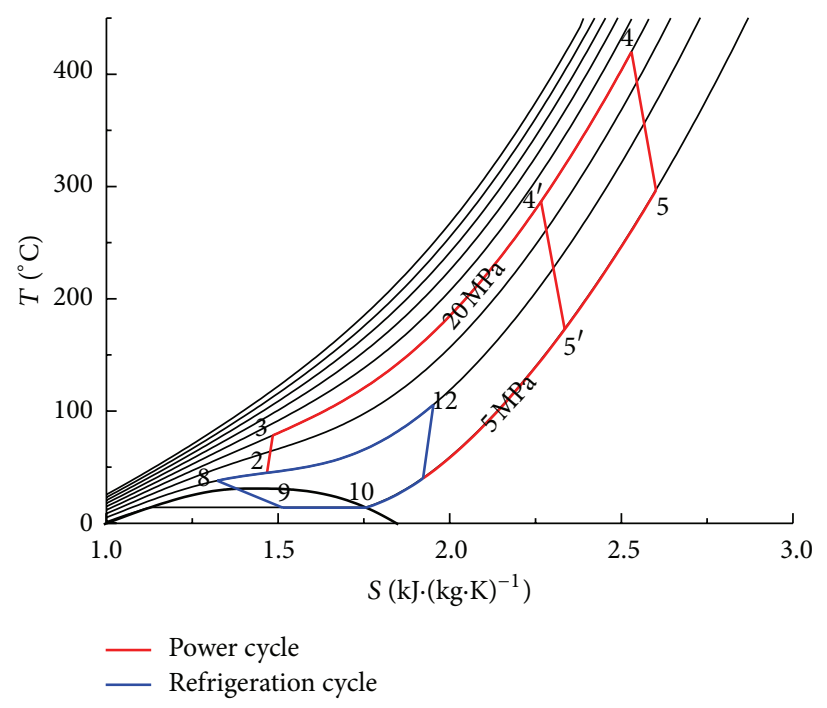

(d) T-S diagram of DDF cycle

FIGURE 4: System layout and T-S diagram of SDF and DDF cycles.

(1) All physical parameters and flow velocity of $\mathrm{CO}_{2}$ on the same cross-section remain constant in these cycles, which means that it is a one-dimensional process.

(2) Flow losses in the pipelines and heat exchangers as well as the leakage of $\mathrm{CO}_{2}$ are neglected.

For the DSF scheme shown in Figure 3(c), the isentropic efficiency of HPC is

$$
\eta_{\mathrm{HPC}}=\frac{\left(h_{3 s}-h_{2}\right)}{\left(h_{3}-h_{2}\right)} .
$$

The power consumption of HPC is

$$
W_{\mathrm{HPC}}=m_{T}\left(h_{3}-h_{2}\right) \text {, }
$$

where $m_{T}$ is the total mass flow rate of $\mathrm{CO}_{2}$ in this power cycle, namely, $m_{T}=m_{H}+m_{L}$.

The thermal balance equation of the gas heater can be expressed as

$$
Q=c_{\mathrm{g}} m_{\mathrm{g}}\left(T_{\mathrm{gi}}-T_{\mathrm{go}}\right)=m_{H}\left(h_{4}-h_{3}\right)
$$

where $c_{\mathrm{g}}$ and $m_{\mathrm{g}}$ are the average specific heat and the mass flow rate of the engine exhaust gas, respectively; $T_{\mathrm{gi}}$ and $T_{\mathrm{go}}$ are the inlet and outlet temperatures of the engine exhaust gas in the gas heater, respectively. 
The isentropic efficiency of HT and LT is

$$
\begin{aligned}
& \eta_{\mathrm{HT}}=\frac{\left(h_{4}-h_{5}\right)}{\left(h_{4}-h_{5 s}\right)}, \\
& \eta_{\mathrm{LT}}=\frac{\left(h_{4^{\prime}}-h_{5^{\prime}}\right)}{\left(h_{4^{\prime}}-h_{5 s^{\prime}}\right)} .
\end{aligned}
$$

Turbine power is

$$
W_{T}=W_{\mathrm{HT}}+W_{\mathrm{LT}}
$$

where $W_{\mathrm{HT}}=m_{H}\left(h_{4}-h_{5}\right)$ and $W_{\mathrm{LT}}=m_{L}\left(h_{4^{\prime}}-h_{5^{\prime}}\right)$.

The thermal balance equation of the fore cooler can be expressed as $h_{11}-h_{10}=h_{2}-h_{8}$.

The cooling capacity is

$$
W_{R}=m_{R}\left(h_{10}-h_{9}\right),
$$

where $m_{R}$ is the mass flow rate of $\mathrm{CO}_{2}$ in the refrigeration cycle.

The isentropic efficiency of LPC is

$$
\eta_{\mathrm{LPC}}=\frac{\left(h_{12 s}-h_{11}\right)}{\left(h_{12}-h_{11}\right)} .
$$

The power consumption of LPC is

$$
W_{\mathrm{LPC}}=m_{R}\left(h_{12}-h_{11}\right) .
$$

The net power output of the system is

$$
W_{\text {net }}=W_{T}-W_{\text {LPC }}-W_{\text {HPC }}
$$

The pressure ratio of the power cycle is

$$
\pi_{T}=\frac{P_{3}}{P_{2}} .
$$

The pressure ratio of the refrigeration cycle is

$$
\pi_{R}=\frac{P_{12}}{P_{11}} .
$$

If the pressure losses of the pipelines and heat exchangers are neglected, then

$$
P_{3}=P_{4}=P_{4^{\prime}}, \quad P_{2}=P_{5}=P_{5^{\prime}}=P_{6}=P_{1}=P_{12} .
$$

For the DDF scheme shown in Figure 3(d), the LPC shares equipment between the power cycle and refrigeration cycle, and its power consumption is

$$
W_{\mathrm{LPC}}=m_{R}\left(h_{12}-h_{11}\right)+m_{T}\left(h_{12}-h_{7}\right) .
$$

The isentropic efficiency of LPC is

$$
\eta_{\mathrm{LPC}}=\frac{m_{R}\left(h_{12 s}-h_{11}\right)+m_{T}\left(h_{12 s}-h_{7}\right)}{m_{R}\left(h_{12}-h_{11}\right)+m_{T}\left(h_{12}-h_{7}\right)} .
$$

The pressure ratio of the power cycle is

$$
\pi_{T}=\frac{P_{3}}{P_{7}} .
$$

The pressure ratio of the refrigeration cycle is

$$
\pi_{R}=\frac{P_{12}}{P_{11}} .
$$

If the pressure loss of the pipelines and heat exchangers is neglected, then

$$
P_{3}=P_{4}=P_{4^{\prime}}, \quad P_{7}=P_{5}=P_{5^{\prime}}=P_{6}=P_{11} .
$$

The calculation formulas of other parameters are the same as that of the DSF cycle. The calculation formulas of the other six kinds of integration schemes can be obtained by simplifying the calculation formulas of the DSF scheme and the DDF scheme.

2.3. Optimization Methods and Operating Conditions. The cooling capacity $\left(W_{R}\right)$, the exhaust temperature of the ICE $\left(T_{\mathrm{gi}}\right)$, and the $\mathrm{CO}_{2}$ temperature in the outlet of the gas cooler $\left(T_{2}\right.$ or $\left.T_{7}\right)$ are the primary independent variables for the above-mentioned waste heat recovery system in the vehicle, which will vary with the ambient temperature, the engine capacity, the engine speed, and so forth. However, the net power output of the waste heat recovery system $\left(W_{\text {net }}\right)$ is the most important dependent variable, which is also the objective function of the thermodynamic system optimization. The maximum $W_{\text {net }}$ can be obtained by selecting the suitable integrated scheme of the thermodynamic system, as well as optimizing the key parameters such as the inlet pressure of the HT $\left(P_{4}\right)$ and the intake pressure of the LPC $\left(P_{2}\right)$.

In this study, a typical internal combustion engine with $200 \mathrm{~kW}$ was used as the object to quantitatively analyze the characteristics of the waste heat recovery system. During design, about $28 \%$ of fuel combustion energy is converted into useful work to drive the vehicle and its accessory loads, and $34 \%$ of fuel combustion energy is carried out by the engine exhaust gases. Therefore, the maximum value of available exhaust heat $\left(Q_{\max }\right)$ is equal to $242.9 \mathrm{~kW}$. If the ambient temperature is $25^{\circ} \mathrm{C}$, the following expression can be used to estimate the heat exchange capacity in the gas heater:

$$
Q=\frac{Q_{\max }\left(T_{\mathrm{gi}}-T_{\mathrm{go}}\right)}{T_{\mathrm{gi}}-25} \mathrm{~kW} .
$$

For maximum utilization of the waste heat, the thermodynamic performance and the key parameters of every integration scheme were optimized through a genetic algorithm. The different integration schemes after parameter optimization were compared and analyzed to determine the optimum matching between the integration scheme and the exhaust parameters of the internal combustion engine. Real-coded, ranking selection, arithmetic crossover, and self-adaptive mutation methods were adopted in this optimization. Based on literature $[26,27]$, the population size, crossover probability, and stop generation were selected to be $50,0.8$, and 400, respectively. The constraint conditions are as follows: the evaporating temperature of $\mathrm{CO}_{2}$ in the refrigeration cycle is equal to $14^{\circ} \mathrm{C}$ and the minimum terminal temperature differences of the gas heater, heat regenerator, and fore-cooler are $30^{\circ} \mathrm{C}, 10^{\circ} \mathrm{C}$, and $10^{\circ} \mathrm{C}$, respectively. In addition, the values of $\eta_{\mathrm{HPC}}, \eta_{\mathrm{LPC}}, \eta_{\mathrm{HT}}$, and $\eta_{\mathrm{LT}}$ were all set as $75 \%$. 


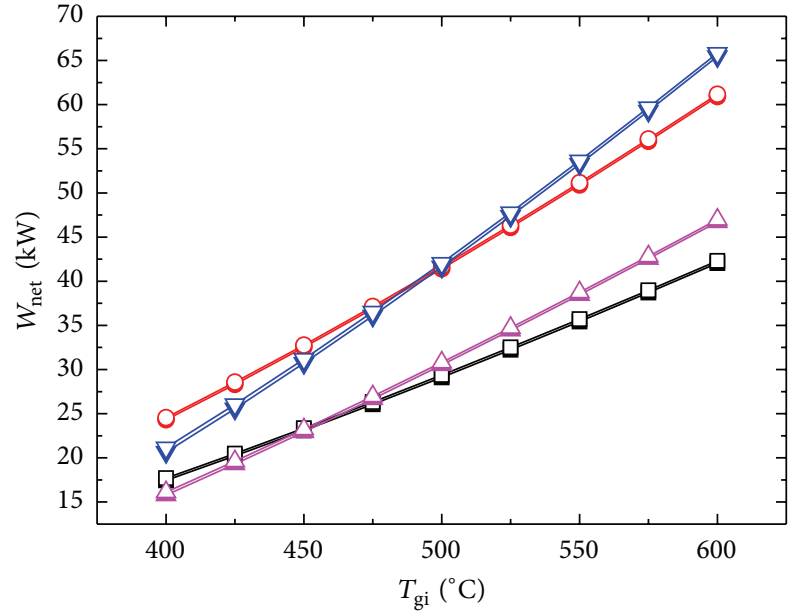

(a) Variation of the maximum net power output versus $T_{\text {gi }}$

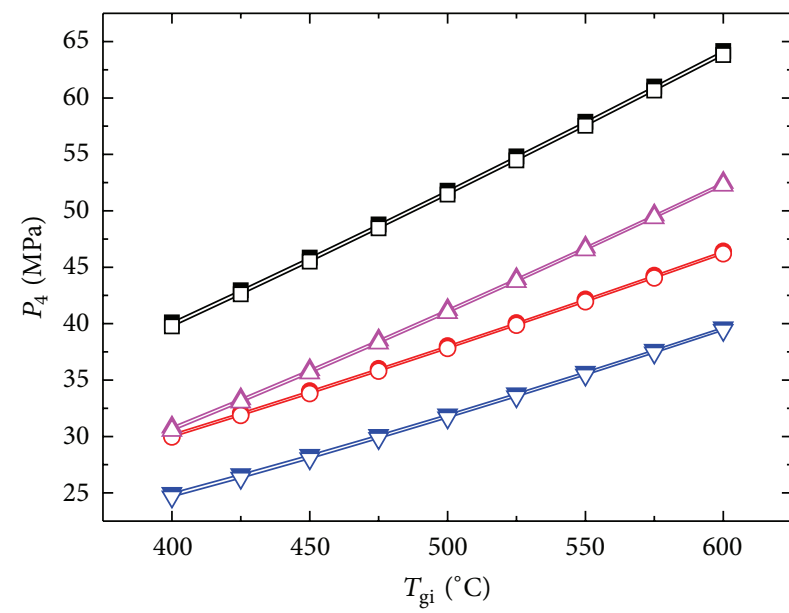

(b) Variation of the optimal value of $P_{4}$ versus $T_{\text {gi }}$

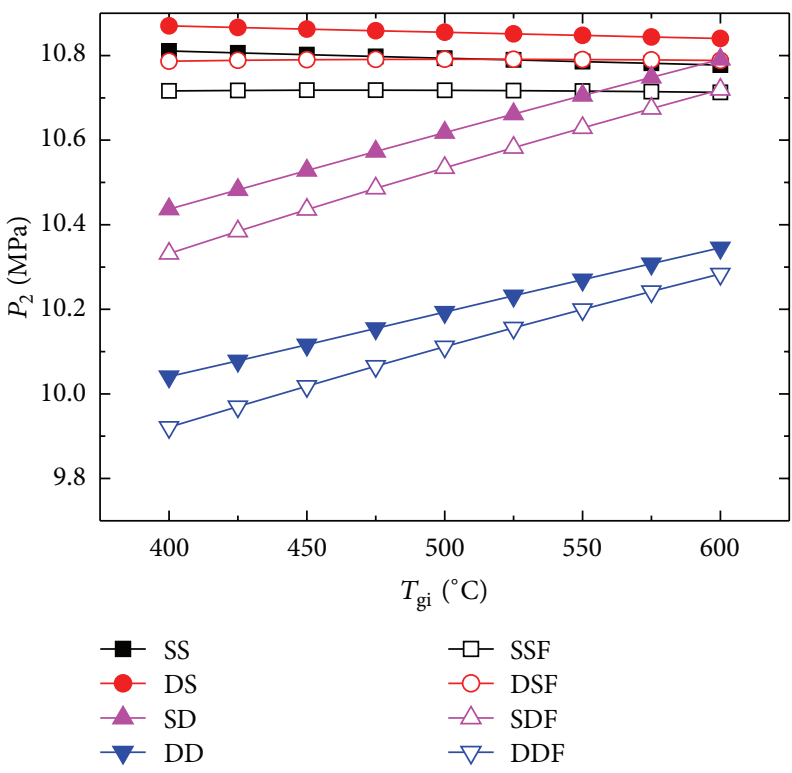

(c) Variation of the optimal value of $P_{2}$ versus $T_{\mathrm{gi}}$

FIGURE 5: Variation of the maximum net power output and the optimal value of parameters $P_{4}$ and $P_{2}$ versus the exhaust temperature of ICE.

\section{Parametric Studies and Optimizations for Thermodynamics Cycles}

3.1. Effect of Different Exhaust Temperature of ICE. The exhaust temperature of ICE $\left(T_{\mathrm{gi}}\right)$ is one of the major variables influencing the system design and parameter optimization, which is closely related with the engine efficiency, engine capacity, engine speed, and so forth. In this section, the key parameters $P_{4}$ and $P_{2}$ were optimized through a genetic algorithm to get an optimum match with the variable $T_{\text {gi }}$ for various integration schemes, in which the net power output $\left(W_{\text {net }}\right)$ was selected as the objective function. Figures 5(a), 5(b), and 5(c) show the variations of the maximum $W_{\text {net }}$ and the optimal $P_{4}, P_{2}$ versus $T_{\text {gi }}$, respectively. Here, $Q_{\max }$ is assumed to be constant, $T_{2}=45^{\circ} \mathrm{C}, T_{10}=14^{\circ} \mathrm{C}$, and $W_{R}=$ $6 \mathrm{~kW}$. It can be seen from these curves that the maximum
$W_{\text {net }}$ and the optimum value of $P_{4}$ increase sharply with the increase in $T_{\text {gi }}$ irrespective of the integration schemes. The maximum $W_{\text {net }}$ and the optimum value of $P_{4}$ at $T_{\mathrm{gi}}=600^{\circ} \mathrm{C}$ are about 2 to 3 times and 1.45-1.7 times as large as that at $T_{\text {gi }}=400^{\circ} \mathrm{C}$, respectively. With the same exhaust parameters for the ICE, the maximum $W_{\text {net }}$ of the double-turbine scheme is $40 \%-50 \%$ higher than that of the single turbine scheme, while the optimum value of $P_{4}$ in the double turbines is $20 \%-$ $35 \%$ lower than that in the single turbine scheme.

There is a significant difference in the maximum $W_{\text {net }}$ between the double-stage compression scheme and the single-stage compression scheme, as shown in Figure 5(a). The growth of maximum $W_{\text {net }}$ in the double-stage compression scheme is faster than that in the single-stage compression scheme with an increase in $T_{\text {gi }}$. However, the maximum $W_{\text {net }}$ of the single-stage compression scheme is higher than that of 


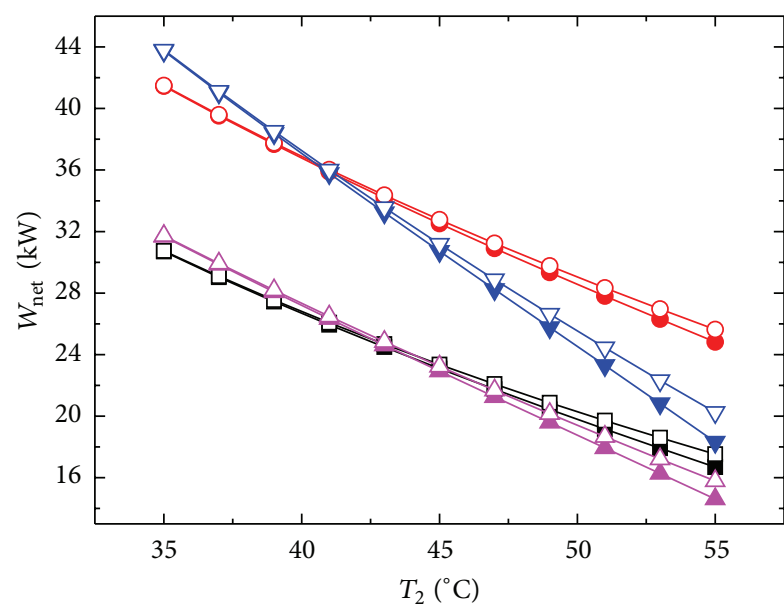

(a) Variation of the maximum net power output versus $T_{2}$

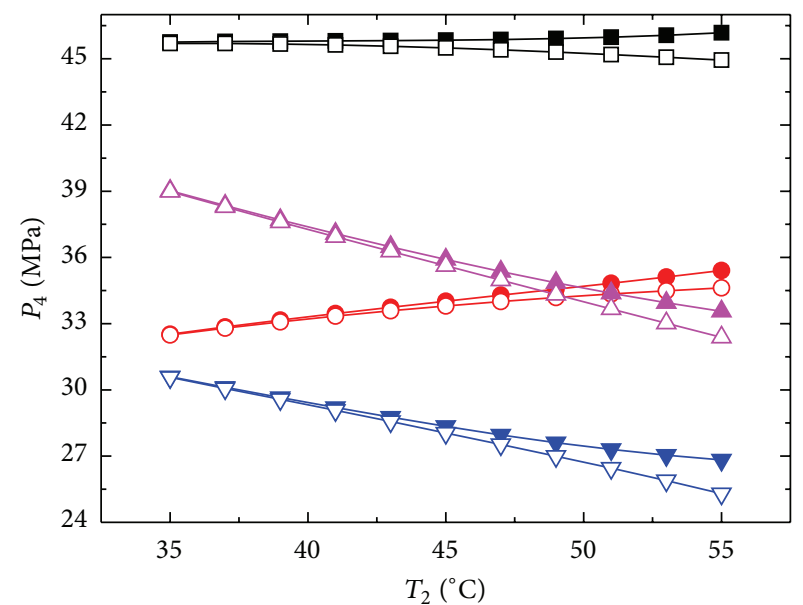

(b) Variation of the optimal value of $P_{4}$ versus $T_{2}$

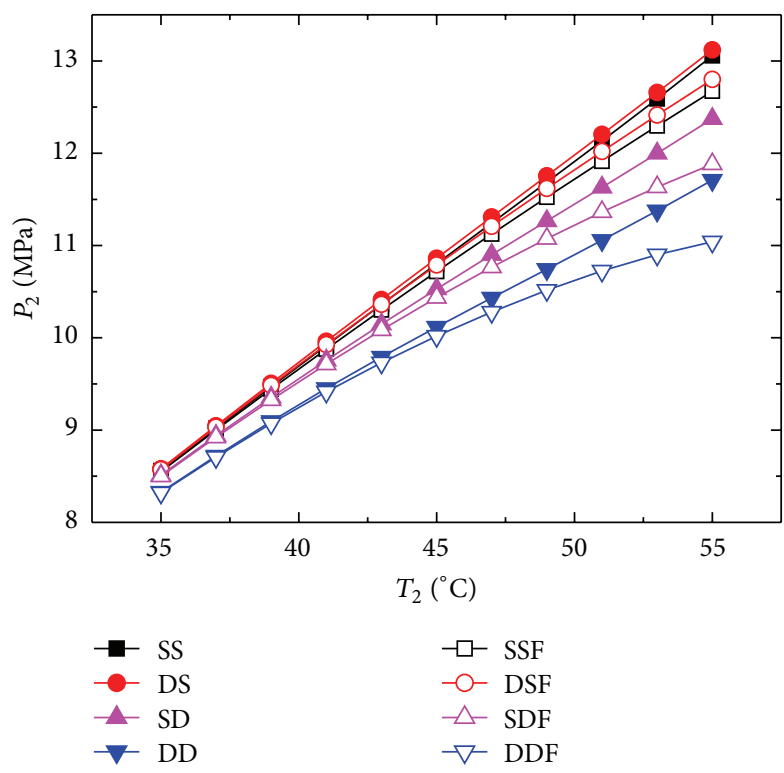

(c) Variation of the optimal value of $P_{2}$ versus $T_{2}$

Figure 6: Variation of the maximum net power output and the optimal value of parameters $P_{4}$ and $P_{2}$ versus $T_{2}$.

the double-stage compression scheme when $T_{\text {gi }}$ is less than $450^{\circ} \mathrm{C}$. In addition, the optimum value of $P_{4}$ in the two-stage compression scheme is $5 \mathrm{MPa}$ to $6 \mathrm{MPa}$ lower than that in the single-stage compression scheme if double turbines are used, while this value is $10 \mathrm{MPa}$ to $12 \mathrm{MPa}$ if a single turbine is used. The optimum value of $P_{4}$ in the DD or DDF scheme is only $60 \%$ of that in the SS or SSF.

Moreover, it can be seen that the absence of the fore cooler has little effect on the maximum $W_{\text {net }}$ and the optimum value of $P_{4}$ irrespective of the integration schemes but requires a higher $P_{2}$. For the single-stage compression scheme, the optimum value of $P_{2}$ does not change with the increase in $T_{\mathrm{gi}}$, while it increases with $T_{\mathrm{gi}}$ for the two-stage compression scheme.

3.2. Effect of the $\mathrm{CO}_{2}$ Temperature in the Outlet of the Gas Cooler. The $\mathrm{CO}_{2}$ temperature in the outlet of the gas cooler
$\left(T_{2}\right)$ is determined primarily by the ambient temperature and the terminal temperature difference of the gas cooler, which is one of the main variables influencing the system design and the parameter optimization. In this section, the optimum values of $P_{4}$ and $P_{2}$ matching with the variable $T_{2}$ were obtained through a genetic algorithm to produce the maximum $W_{\text {net }}$ corresponding to every integration scheme. Figures 6(a), 6(b), and 6(c) show the variations of the maximum $W_{\text {net }}$ and the optimal $P_{4}, P_{2}$ versus $T_{2}$, respectively. Here, $Q_{\max }$ is assumed to be constant, $T_{\mathrm{gi}}=450^{\circ} \mathrm{C}, T_{10}=$ $14^{\circ} \mathrm{C}$, and $W_{R}=6 \mathrm{~kW}$. It can be seen that the maximum $W_{\text {net }}$ decreases with the increase in $T_{2}$ irrespective of the integration scheme. The maximum $W_{\text {net }}$ at $T_{2}=55^{\circ} \mathrm{C}$ is only $40 \%-60 \%$ of that at $T_{2}=35^{\circ} \mathrm{C}$. In addition, the variation of $T_{2}$ has a greater influence on the maximum $W_{\text {net }}$ of twostage compression schemes than on that of the single-stage compression schemes, especially for the DD scheme and the 


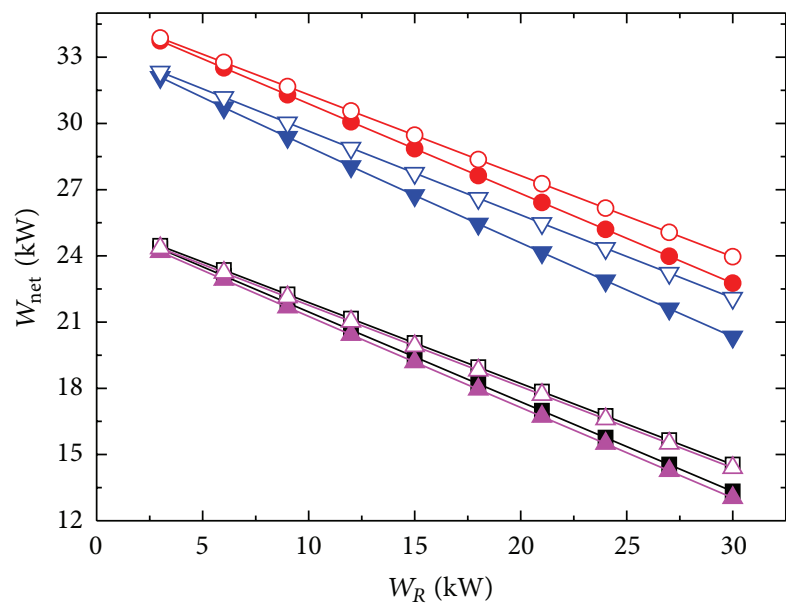

(a) Variation of the maximum net power output versus $W_{R}$

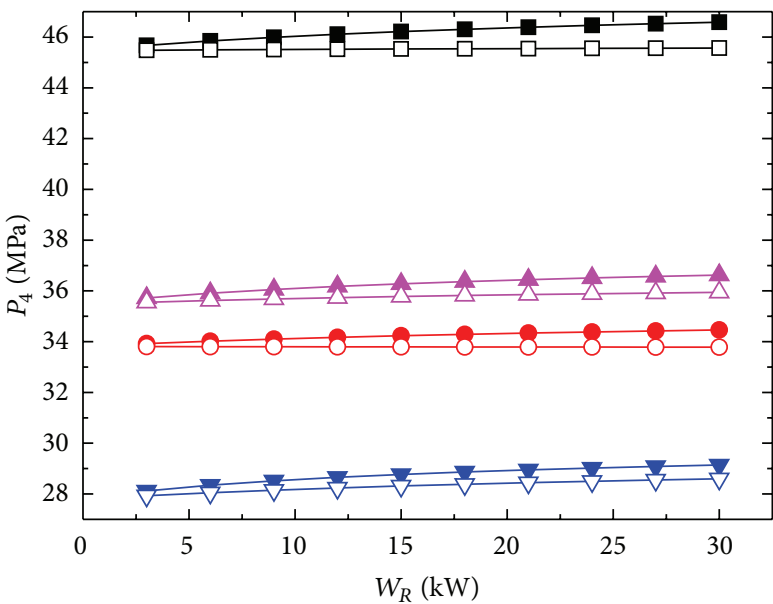

(b) Variation of the optimal value of $P_{4}$ versus $W_{R}$

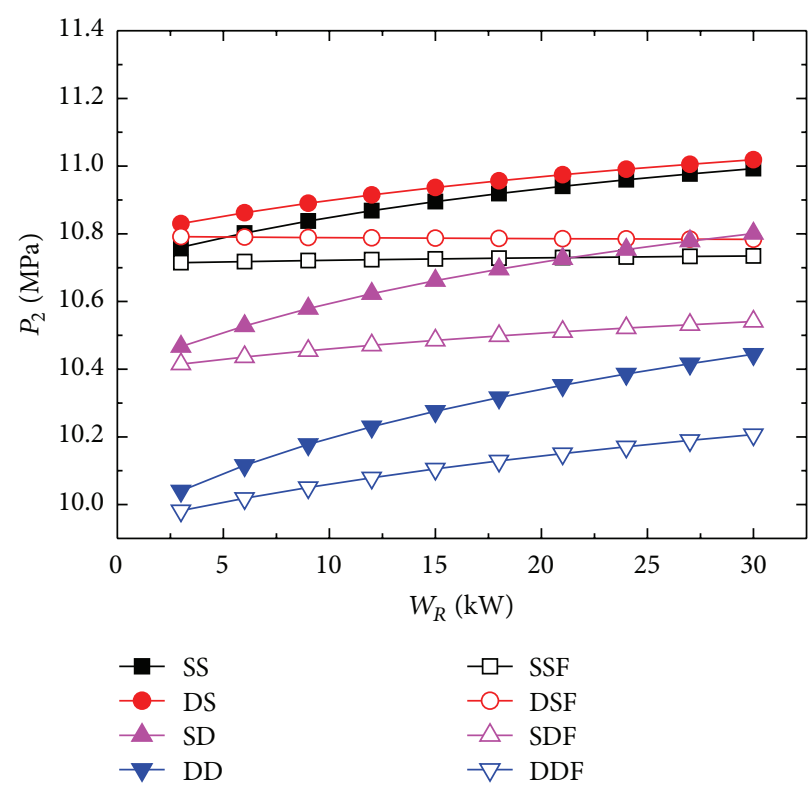

(c) Variation of the optimal value of $P_{2}$ versus $W_{R}$

FigURE 7: Variation of the maximum net power output and the optimal value of parameters $P_{4}$ and $P_{2}$ versus $W_{R}$.

DDF scheme. The maximum $W_{\text {net }}$ of the DD scheme and the DDF scheme is not only lower than that of the DS scheme at $T_{2}>41^{\circ} \mathrm{C}$, but also decreases quickly with an increase in $T_{2}$. The maximum $W_{\text {net }}$ of the DD scheme and DDF scheme is close to that of single turbine schemes at $T_{2}=55^{\circ} \mathrm{C}$, while the maximum $W_{\text {net }}$ of the DS scheme and DSF scheme is always about $10 \mathrm{~kW}$ to $12 \mathrm{~kW}$ higher than that of the single turbine schemes.

As shown in Figures 6(b) and 6(c), the optimum value of $P_{4}$ decreases with an increase in $T_{2}$ in the two-stage compression schemes. However, the optimum value of $P_{4}$ increases with an increase in $T_{2}$ in the single-stage compression schemes (e.g., DS scheme) or remains constant (e.g., SS scheme). Furthermore, the optimum value of $P_{2}$ increases with an increase in $T_{2}$. The optimum value of $P_{2}$ at $T_{2}=55^{\circ} \mathrm{C}$ is about 1.3 to 1.5 times that of at $T_{2}=35^{\circ} \mathrm{C}$.
Different integration schemes show a significant difference in the optimum value of $P_{2}$ and the optimal $P_{2}$ increases gradually in the order of DD, SD, SS, and DS schemes. The fore cooler is able to increase maximum $W_{\text {net }}$ and decrease the optimum value of $P_{4}$, and $P_{2}$, but its effect on $W_{\text {net }}$ and $P_{4}$ can be neglected compared to other factors.

3.3. Effect of Different Cooling Capacities. In the combined power and refrigeration generation with the $\mathrm{CO}_{2}$ thermodynamic cycle, the cooling capacity $\left(W_{R}\right)$ is another major variable influencing the system design and parameter optimization that is closely related to the spatial size needing to be cooled, the sealing performance of the compartment, and the ambient temperature. In this section, the optimum values of $P_{4}$ and $P_{2}$ matching with the variable $W_{R}$ were obtained 
through a genetic algorithm to produce the maximum $W_{\text {net }}$ corresponding to every integration scheme. Figures $7(\mathrm{a})$, $7(\mathrm{~b})$, and $7(\mathrm{c})$ show the variations of the maximum $W_{\text {net }}$ and the optimal $P_{4}, P_{2}$ versus $W_{R}$, respectively. Here, $T_{\mathrm{gi}}=$ $450^{\circ} \mathrm{C}, T_{10}=14^{\circ} \mathrm{C}$, and $T_{2}=45^{\circ} \mathrm{C}$. It can be seen that the maximum $W_{\text {net }}$ decreases linearly with increasing $W_{R}$, while the optimum values of $P_{4}$ and $P_{2}$ increase slightly with increasing $W_{R}$.

The cycles with the fore cooler have a slightly higher $W_{\text {net }}$ than the cycles without fore cooler, which is more obvious in the double-turbine schemes than in the single turbine schemes. In addition, the difference in the maximum $W_{\text {net }}$ increases with increasing $W_{R}$ between the DD scheme and the DDF scheme or the DS scheme and the DSF scheme. When $W_{R}$ is equal to $30 \mathrm{~kW}$, the difference in the maximum $W_{\text {net }}$ is $2.5 \mathrm{~kW}$ between the DDF scheme and the DD scheme, while it is $1.5 \mathrm{~kW}$ between the DSF scheme and the DS scheme. Moreover, the optimum values of $P_{4}$ and $P_{2}$ for the schemes with fore cooler are smaller than that of the schemes without fore cooler, whose difference increases with $W_{R}$. The optimal values for $P_{4}$ and $P_{2}$ of the schemes with fore cooler are $0.6 \mathrm{MPa}$ to $1.0 \mathrm{MPa}$ and $0.2 \mathrm{MPa}$ to $0.3 \mathrm{MPa}$ lower than that of the schemes without fore cooler, respectively. However, $W_{R}$ has little effect on the scheme selection and parameter optimization compared to $T_{2}$ and $T_{\text {gi }}$. In order to downsize the system, the fore cooler can be removed from the cycle as $W_{R}$ is far lower than $W_{\text {net }}$.

\section{Conclusions}

In this paper, a new thermodynamic system was proposed to recover the waste heat of the internal combustion engine by integrating the transcritical $\mathrm{CO}_{2}$ refrigeration cycle with the supercritical $\mathrm{CO}_{2}$ power cycle, and eight kinds of integration schemes were developed. The key parameters of the system were optimized through a genetic algorithm to get the optimum match with different variables and schemes, in which the net power output $\left(W_{\text {net }}\right)$ was selected as the objective function. The main conclusions were as follows.

(1) Replacing a single turbine scheme with a doubleturbine scheme can significantly enhance the net power output $\left(W_{\text {net }}\right)$ and lower the inlet pressure of a power turbine $\left(P_{4}\right)$. With the same exhaust parameters of the ICE, the maximum $W_{\text {net }}$ of a double-turbine scheme is $40 \%-50 \%$ higher than that of the single turbine scheme, while the optimum value of $P_{4}$ in the double turbines is $20 \%-35 \%$ lower than that in the single turbine scheme. Replacing a single-stage compression scheme with a double-stage compression scheme can also lower the value of $P_{4}$, while it could not always significantly enhance the value of $W_{\text {net }}$. The optimum value of $P_{4}$ in the DD or DDF scheme is only $60 \%$ that in the SS or SSF scheme.

(2) The maximum $W_{\text {net }}$ decreases with the increase in the $\mathrm{CO}_{2}$ temperature in the outlet of the gas cooler $\left(T_{2}\right)$ and the variation of $T_{2}$ has a greater influence on the maximum $W_{\text {net }}$ of two-stage compression schemes than on that of the single-stage compression schemes.
In addition, the optimum value of $P_{4}$ decreases with the increase in $T_{2}$ in the two-stage compression schemes. However, the optimum value of $P_{4}$ increases with the increase in $T_{2}$ in the single-stage compression schemes (e.g., DS scheme) or remains constant (e.g., SS scheme).

(3) The effect of the fore cooler on the overall performance of the thermodynamic system can be neglected as it is much lower than the net power output. In most cases, the fore cooler can be removed to downsize the system.

(4) The integration scheme of the double turbines with the two-stage compression has significant advantages in improving the thermal power conversion efficiency and reducing the turbine inlet pressure. Except for the power consumption of air conditioning, the net power output of this thermodynamic system can reach up to $13 \%-35 \%$ of the engine power when it is used to recover the exhaust heat of an internal combustion engine.

\section{Nomenclature}

$\mathrm{CO}_{2}$ : Carbon dioxide

DD: Integration system of the double-turbine power cycle with double-stage compression and a refrigeration cycle

DDF: DD scheme with fore cooler

DS: Integration system of the double-turbine power cycle with single-stage compression and a refrigeration cycle

DSF: DS scheme with fore cooler

G: Generator

$h: \quad$ Enthalpy $(\mathrm{kJ} / \mathrm{kg})$

HPC: High pressure compressor

HT: High-temperature turbine

ICE: Internal combustion engine

LT: Low-temperature turbine

LPC: Low pressure compressor

$m$ : Mass flow rate $(\mathrm{kg} / \mathrm{s})$

ORC: Organic Rankine cycle

$P$ : $\quad$ Pressure $(\mathrm{MPa})$

$Q: \quad$ Heat exchange capacity in the gas heater $(\mathrm{kJ})$

S: $\quad$ Entropy $(\mathrm{kJ} /(\mathrm{kg} \cdot \mathrm{K}))$

$\mathrm{SD}$ : Integration system of the single-turbine power cycle with double-stage compression and a refrigeration cycle

SDF: SD scheme with fore cooler

SS: Integration system of the single-turbine power cycle with single-stage compression and a refrigeration cycle

SSF: SS scheme with fore cooler

T: $\quad$ Temperature $\left({ }^{\circ} \mathrm{C}\right)$

$W: \quad$ Power $(\mathrm{kW})$

$W_{\text {net }}$ : Net power output $(\mathrm{kW})$. 


\section{Greek Symbols}

$\eta$ : Efficiency

$\pi$ : Pressure ratio.

\section{Subscripts}

g: Exhaust gas

gi: Exhaust gas inlet of gas heater

go: Exhaust gas outlet of gas heater

$R: \quad$ Refrigeration cycle

$T: \quad$ Power cycle

1, 6: $\quad \mathrm{CO}_{2}$ inlet of gas cooler

2: $\quad \mathrm{CO}_{2}$ inlet of HPC

3: $\quad \mathrm{CO}_{2}$ inlet of gas heater

4, 4s: $\quad \mathrm{CO}_{2}$ inlet of HT

$4^{\prime}, 4 s^{\prime}: \mathrm{CO}_{2}$ inlet of LT

5,5s: $\quad \mathrm{CO}_{2}$ outlet of HT

$5^{\prime}, 5 s^{\prime}: \mathrm{CO}_{2}$ outlet of LT

7, 11: $\mathrm{CO}_{2}$ inlet of LPC

8: $\quad \mathrm{CO}_{2}$ outlet of fore cooler

9: $\quad \mathrm{CO}_{2}$ inlet of evaporator

10: $\mathrm{CO}_{2}$ outlet of evaporator

12: $\quad \mathrm{CO}_{2}$ outlet of LPC

max: Maximum value.

\section{Conflict of Interests}

The authors declare that there is no conflict of interests regarding the publication of this paper.

\section{Acknowledgments}

The authors are thankful for the financial support of the Fundamental Research Funds for the Central Universities and National Natural Science Foundation of China (NSFC) (no. 50476051).

\section{References}

[1] W. Jansen, A. M. Heitmann, and M. Hanawa, "Recovery of automobile engine exhaust energy," in Proceedings of the ASME Turbo Expo, pp. 733-739, June 2008.

[2] M. Bianchi and A. De Pascale, "Bottoming cycles for electric energy generation: parametric investigation of available and innovative solutions for the exploitation of low and medium temperature heat sources," Applied Energy, vol. 88, no. 5, pp. 1500-1509, 2011.

[3] B. Song, W. Zhuge, R. Zhao et al., "An investigation on the performance of a Brayton cycle waste heat recovery system for turbocharged diesel engines," Journal of Mechanical Science and Technology, vol. 27, no. 6, pp. 1721-1729, 2013.

[4] M. J. Lee, D. L. Tien, and C. T. Shao, "Thermophysical capability of ozone-safe working fluids for an organic rankine cycle system," Heat Recovery Systems and CHP, vol. 13, no. 5, pp. 409418, 1993.

[5] M. Persichilli, T. Held, S. Hostler, E. Zdankiewicz, and D. Klapp, "Transforming waste heat to power through development of a $\mathrm{CO}_{2}$-based-power cycle," in Proceedings of the Electric Power Expo, pp. 8-10, Rosemount, Ill, USA, May 2011.
[6] M. Persichilli, A. Kacludis, E. Zdankiewicz, and T. Held, "Supercritical $\mathrm{CO}_{2}$ power cycle developments and commercialization: why $\mathrm{sCO}_{2}$ can displace steam," in Proceedings of the Power-Gen India \& Central Asia, New Delhi, India, April 2012.

[7] Y. Chen, P. Lundqvist, A. Johansson, and P. Platell, "A comparative study of the carbon dioxide transcritical power cycle compared with an organic rankine cycle with R123 as working fluid in waste heat recovery," Applied Thermal Engineering, vol. 26, no. 17-18, pp. 2142-2147, 2006.

[8] X. D. Niu, H. Yamaguchi, X. R. Zhang, Y. Iwamoto, and N. Hashitani, "Experimental study of heat transfer characteristics of supercritical $\mathrm{CO}_{2}$ fluid in collectors of solar Rankine cycle system," Applied Thermal Engineering, vol. 31, no. 6-7, pp. 12791285, 2011.

[9] F. Vélez, J. Segovia, F. Chejne, G. Antolín, A. Quijano, and M. Carmen Martín, "Low temperature heat source for power generation: exhaustive analysis of a carbon dioxide transcritical power cycle," Energy, vol. 36, no. 9, pp. 5497-5507, 2011.

[10] E. Cayer, N. Galanis, M. Desilets, H. Nesreddine, and P. Roy, "Analysis of a carbon dioxide transcritical power cycle using a low temperature source," Applied Energy, vol. 86, no. 7-8, pp. 1055-1063, 2009.

[11] Y.-J. Baik, M. Kim, K. C. Chang, and S. J. Kim, "Power-based performance comparison between carbon dioxide and R125 transcritical cycles for a low-grade heat source," Applied Energy, vol. 88, no. 3, pp. 892-898, 2011.

[12] H. Chen, D. Y. Goswami, and E. K. Stefanakos, "A review of thermodynamic cycles and working fluids for the conversion of low-grade heat," Renewable and Sustainable Energy Reviews, vol. 14, no. 9, pp. 3059-3067, 2010.

[13] X. R. Zhang and H. Yamaguchi, "An experimental study on evacuated tube solar collector using supercritical $\mathrm{CO}_{2}$," Applied Thermal Engineering, vol. 28, no. 10, pp. 1225-1233, 2008.

[14] X. R. Zhang, H. Yamaguchi, D. Uneno, K. Fujima, M. Enomoto, and N. Sawada, "Analysis of a novel solar energy-powered Rankine cycle for combined power and heat generation using supercritical carbon dioxide," Renewable Energy, vol. 31, no. 12, pp. 1839-1854, 2006.

[15] V. Dostal, A supercritical carbon dioxide cycle for next generation nuclear reactors [Ph.D. thesis], Massachusetts Institute of Technology, 2004.

[16] D. E. Boewe, C. W. Bullard, J. M. Yin, and P. S. Hrnjak, "Contribution of internal heat exchanger to transcritical R-744 cycle performance," HVAC and R Research, vol. 7, no. 2, pp. 155168,2001

[17] V. Dostal, P. Hejzlar, and M. J. Driscoll, "The supercritical carbon dioxide power cycle: comparison to other advanced power cycles," Nuclear Technology, vol. 154, no. 3, pp. 283-301, 2006.

[18] Y. M. Kim, C. G. Kim, and D. Favrat, “Transcritical or supercritical $\mathrm{CO}_{2}$ cycles using both low- and high-temperature heat sources," Energy, vol. 43, no. 1, pp. 402-415, 2012.

[19] M. Li, J. Wang, S. Li, X. Wang, W. He, and Y. Dai, “Thermoeconomic analysis and comparison of a $\mathrm{CO}_{2}$ transcritical power cycle and an organic rankine cycle," Geothermics, vol. 50, pp. 101-111, 2014.

[20] P. Nekså, $\mathrm{CO}_{2}$ as Refrigerant for Systems in Transcritical Operation, pp. 28-32, 2004.

[21] J. Kohler, M. Sonnekalb, H. Kaiser, and W. Koecher, Carbon Dioxide as a Refrigerant for Vehicle Air-Conditionig with Application to Bus Air-Conditioning, pp. 23-25, 1995. 
[22] M. Sonnekalb and J. Köhler, Transport Refrigeration with a Transcritical Refrigeration Cycle Using Carbon Dioxide as Refrigerant, pp.124-33, 1997.

[23] K. Martin, G. Lang, and R. Rieberer, "Mobile HVAC-system with $\mathrm{CO}_{2}$ as refrigerant-simulations and Measurements," SAE Technical Papers, pp. 4-7, 2005.

[24] H. Liu, J. Chen, and Z. Chen, "Experimental investigation of a $\mathrm{CO}_{2}$ automotive air conditioner," International Journal of Refrigeration, vol. 28, no. 8, pp. 1293-1301, 2005.

[25] Y. Chen, P. Lundqvist, and P. Platell, "Theoretical research of carbon dioxide power cycle application in automobile industry to reduce vehicle's fuel consumption," Applied Thermal Engineering, vol. 25, no. 14-15, pp. 2041-2053, 2005.

[26] Y. Dai, J. Wang, and L. Gao, "Parametric optimization and comparative study of organic Rankine cycle (ORC) for low grade waste heat recovery," Energy Conversion and Management, vol. 50, no. 3, pp. 576-582, 2009.

[27] J. Wang, Z. Sun, Y. Dai, and S. Ma, "Parametric optimization design for supercritical $\mathrm{CO}_{2}$ power cycle using genetic algorithm and artificial neural network," Applied Energy, vol. 87, no. 4, pp. 1317-1324, 2010. 


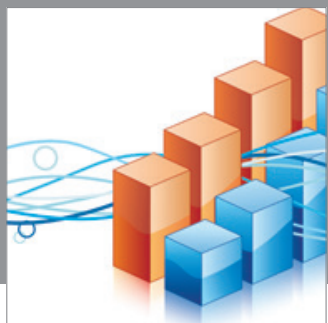

Advances in

Operations Research

mansans

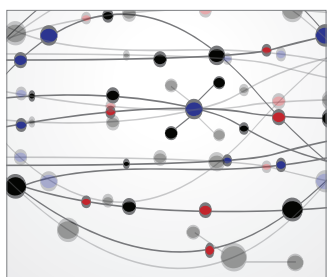

The Scientific World Journal
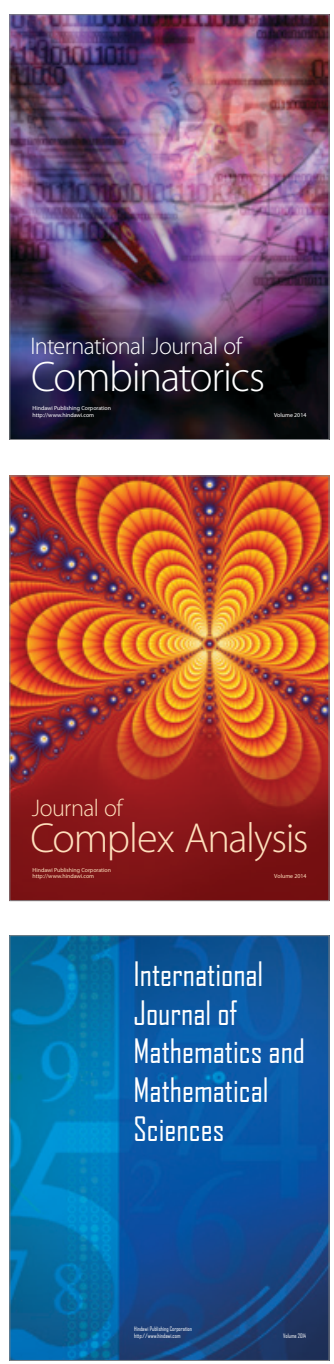
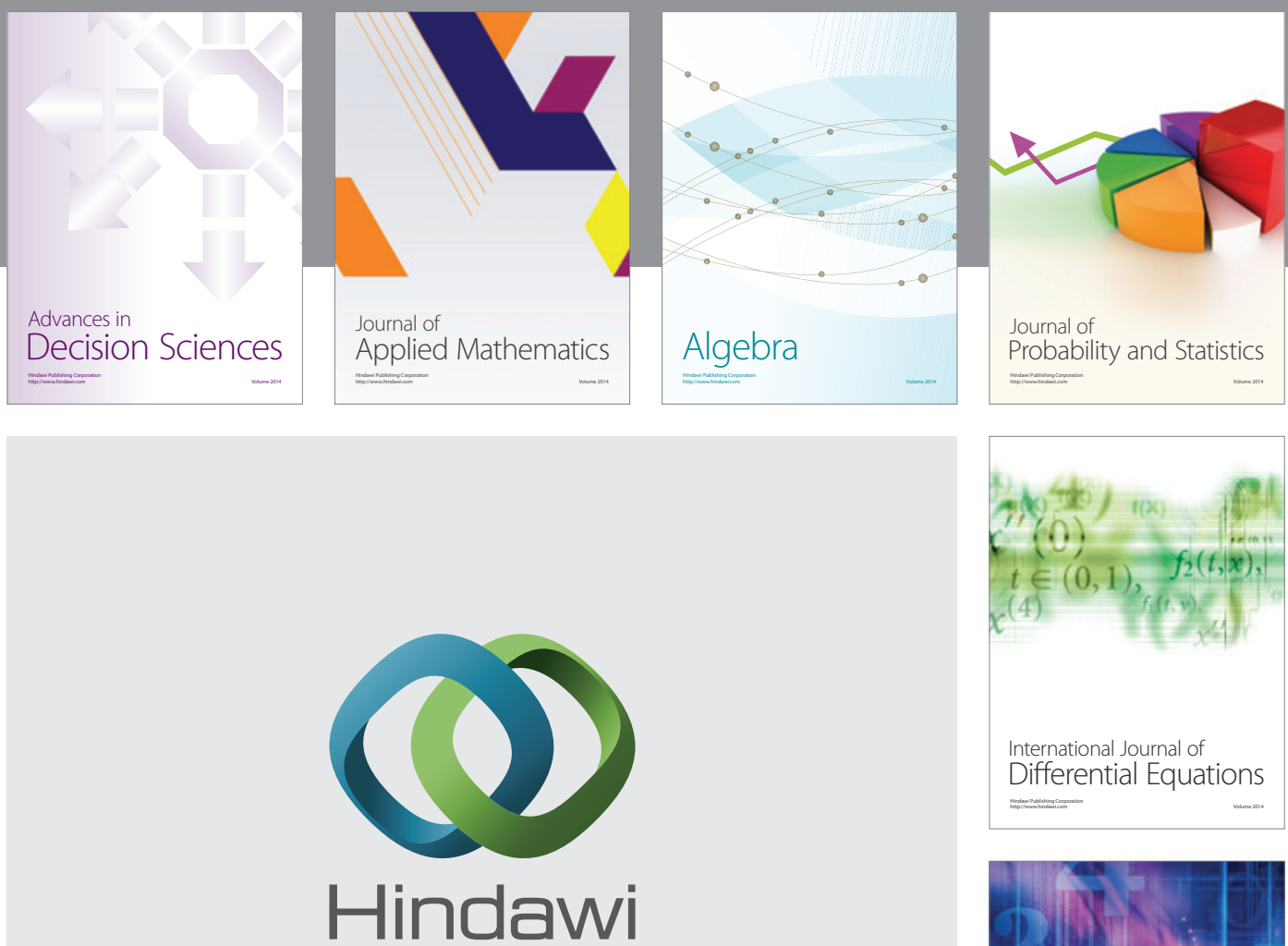

Submit your manuscripts at http://www.hindawi.com
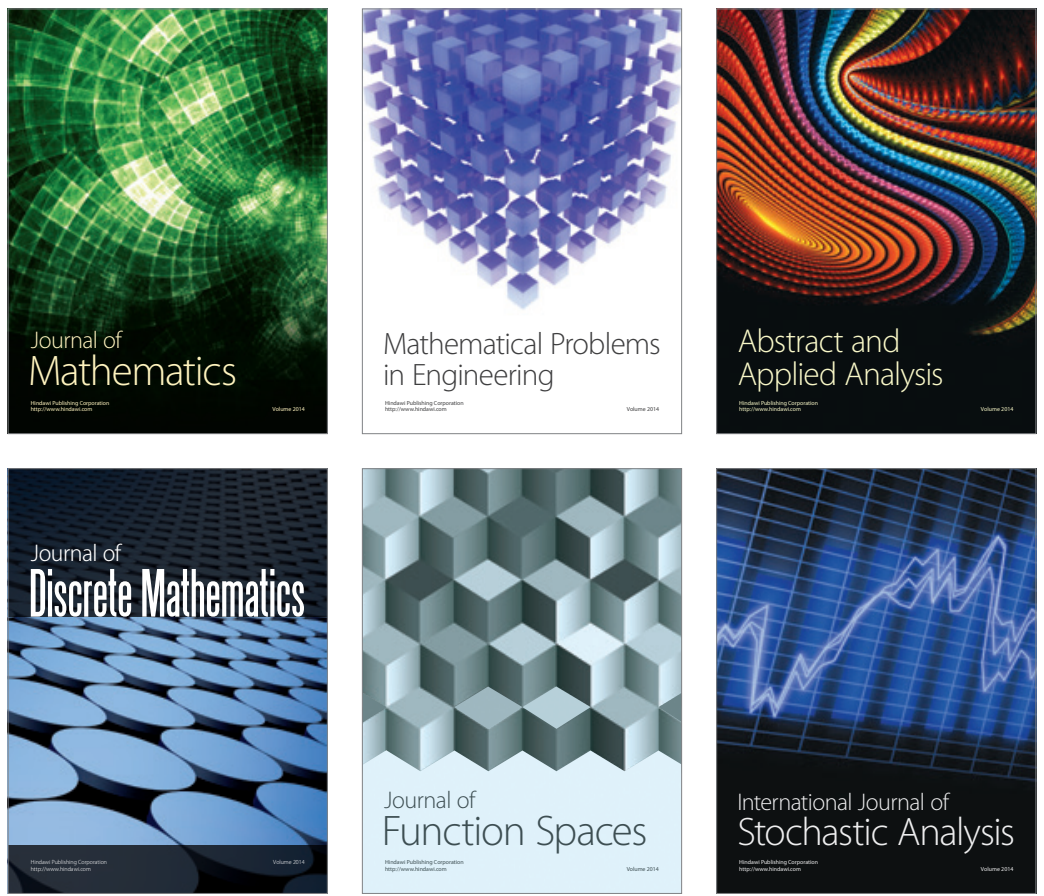

Journal of

Function Spaces

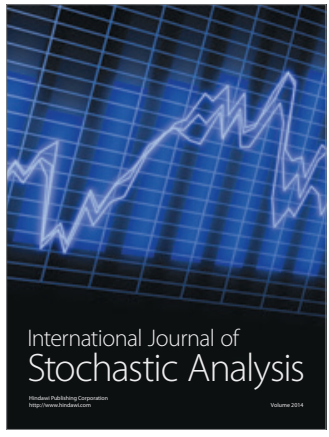

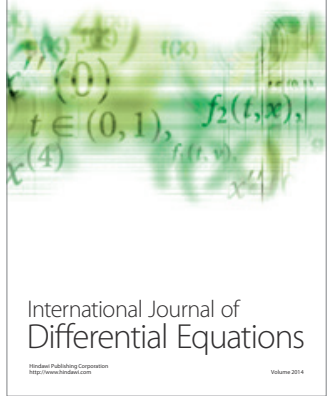
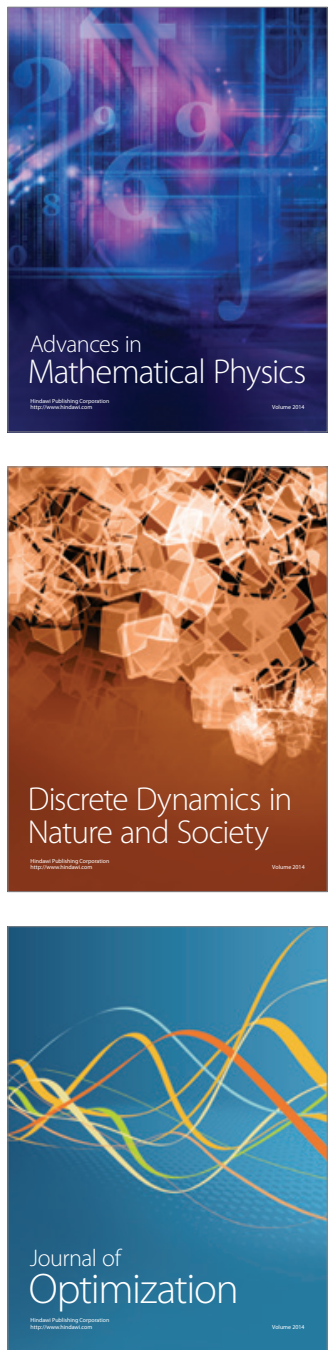